\title{
Postpartum domperidone use in British Columbia: a retrospective cohort study
}

\author{
Kate Smolina PhD, Steven G. Morgan PhD, Gillian E. Hanley PhD, Tim F. Oberlander MD, \\ Barbara Mintzes PhD
}

\section{Abstract}

Background: Domperidone is commonly used off-label to stimulate milk production in mothers who have low milk supply. The aim of this study was to describe trends, patterns and determinants of postpartum domperidone use.

Methods: This is a retrospective, population-based study involving all women with a live birth between Jan. 1, 2002, and Dec. 31, 2011, in the province of British Columbia. We examined administrative data sets containing person-specific information on filled prescriptions and use of medical services, and we used logistic regression to examine associations between domperidone use and maternal characteristics.

Results: The study population consisted of 225532 women with 320351 live births. The prevalence of postpartum domperidone use more than doubled between 2002 and 2011. In 2011, 1 in 3 women with a preterm birth and 1 in 5 women with a full-term birth were prescribed domperidone in the first 6 months postpartum. Women who were older, had a higher body mass index, had a chronic disease, were first-time mothers, delivered more than 1 baby (multiple pregnancy), had a preterm birth or had a cesarian delivery were more likely to fill a postpartum domperidone prescription.

Interpretation: We found an increase in postpartum domperidone use over a 10-year period. More research is needed on maternal and infant health outcomes.

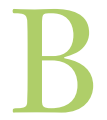

reastfeeding is strongly encouraged over formula feeding because of multiple health benefits for infants, including improved gastrointestinal function and decreased risk of acute respiratory and gastrointestinal infections as well as otitis media. ${ }^{1}$ Difficulty in establishing adequate milk supply is a common challenge, and prescription drugs may be seen as an attractive solution.

Domperidone, a dopamine antagonist available in Canada since 1985 , is used to increase upper gastrointestinal motility and to prevent treatment-related gastrointestinal symptoms in patients with Parkinson disease. It also increases prolactin levels, and its use to stimulate lactation was first described more than 30 years ago. ${ }^{2}$ However, domperidone has not been approved for this indication in Canada. Yet in a recent study of prescription drug use during pregnancy and the postpartum period in British Columbia, ${ }^{3}$ we identified domperidone to be the most commonly prescribed drug during the first 6 months postpartum.

Limited evidence suggests that domperidone can increase milk supply, especially following preterm birth. ${ }^{4-7}$ A doseresponse relation remains uncertain, as 2 small studies failed to indicate a clear advantage with higher doses, ${ }^{8,9}$ and large- scale studies are lacking. A multicentre trial in preterm births, still ongoing in 2015 , aims to randomly assign 560 women to 2 groups and follow them for 28 days at $30 \mathrm{mg} / \mathrm{d}$, the first 2 weeks placebo-controlled. ${ }^{10}$

Importantly, maternal and infant safety have not been established. During the 2000s, approved product information in Canada discouraged domperidone use during breastfeeding and recommended doses of $30-40 \mathrm{mg} / \mathrm{d}$, up to a maximum of $80 \mathrm{mg} / \mathrm{d}$ for severe or resistant gastrointestinal disorders. ${ }^{11}$ Health Canada published safety advisories for domperidone in March $2012^{12}$ and January $2015,{ }^{13}$ urging caution with use and, in 2015 , limiting doses for all indications to $30 \mathrm{mg} / \mathrm{d}$. The initial 2012 warning was based on 2 observational studies that reported significant associations between domperidone

Competing interests: None declared.

This article has been peer reviewed.

Correspondence to: Kate Smolina, kate.smolina@ubc.ca CMAJ Open 2016. DOI:10.9778/cmajo.20150067 
use and ventricular arrhythmia and sudden cardiac death. ${ }^{14,15}$ However, because the study population included older patients (mean age in the 70s), many questioned the Health Canada warning and its applicability to a younger, relatively healthier patient population of breastfeeding women. ${ }^{16,17}$ Even less is known about the effect of domperidone on the nursing infant. The drug is detected at low levels in breast milk, ${ }^{11}$ and there are reports of QT prolongation with domperidone exposure at therapeutic levels in infants. ${ }^{18}$

The aim of this study was to examine trends in postpartum domperidone use in BC from 2002 to 2011. We examined the frequency of domperidone use over this time period, doses, duration and characteristics of women receiving domperidone prescriptions.

\section{Methods}

\section{Data sources}

Our analysis is based on de-identified, linked health data sets provided by Perinatal Services BC and Population Data BC with approval of relevant data stewards. ${ }^{19-22}$ All inferences, opinions and conclusions drawn in this publication are those of the authors, and do not reflect the opinions or policies of Perinatal Services BC or Population Data BC. Data sets included health care and sociodemographic information for all $\mathrm{BC}$ residents except those whose prescription drug coverage fell under federal jurisdiction (i.e., military veterans, registered First Nations people and Inuit, and federal penitentiary inmates, who collectively make up about $4 \%$ of the BC population).

Information about maternal and infant health came from Perinatal Services BC's Perinatal Data Registry. This province-wide database includes information on antenatal, intrapartum/delivery and postpartum maternal and infant care and outcomes for nearly all births in BC (about 99\%). Some information on maternal reproductive history (e.g., previous miscarriages, stillbirths and premature deliveries) and health behaviours during pregnancy (e.g., smoking) is also recorded. The validity of the registry variables concerning maternal characteristics, newborn characteristics and delivery information that were used in this study is very high. ${ }^{23}$

The registry data were linked to information about women's prescription drug dispensations, medical services use, hospital admissions and income, as well as vital statistics for their babies. Information about domperidone dispensations came from PharmaNet, an information system that records every prescription filled at a pharmacy outside of acute care hospitals in BC, regardless of patient age or insurance status. Medical and hospital data were obtained from BC's universal, public health insurance program. Income quintiles were estimated using government records of the average adjusted household income in each patient's neighbourhood, with neighbourhoods including about 400-700 residents. ${ }^{24}$

\section{Study population}

We identified all women in the Perinatal Data Registry with a live birth between Jan. 1, 2002, and Dec. 31, 2011. To ensure accurate capture of domperidone dispensations and health information for all women in our cohort, we excluded women who did not reside in $\mathrm{BC}$ for at least 275 days in each year from 1 year preconception to 1 year postdelivery $(n=32143)$.

We used the Aggregated Diagnosis Groups of the Johns Hopkins Adjusted Clinical Groups Case-Mix System (version 10.0) to identify women with chronic conditions based on diagnoses recorded in hospital and physician billing records. The case-mix system has been shown to be predictive of both drug use and expenditure in the $\mathrm{BC}$ population. ${ }^{25}$

Vital statistics data provided exact dates of birth for all babies born to the women in our cohort. For more than $90 \%$ of the study population, we were able to compute reliable gestational age estimates based on information from earlygestation ultrasonography, date of last menstrual period, infant clinical examination and/or chart documentation.

\section{Outcome variables}

Based on the date the prescription was filled, we characterized patterns of domperidone use using the following metrics: prevalence of use among women in the postpartum period; number of domperidone dispensations; daily dose per domperidone prescription; duration of individual prescriptions; timing of dispensation of the first prescription; and total days of domperidone therapy during the first 6 months postpartum. We examined all outcome variables by the type of birth (preterm or term). When there were clinically meaningful differences, we report the results separately; otherwise, we report pooled results.

To better understand the indication for which domperidone was prescribed, we examined the specialty of the prescribing physician and recorded diagnosis in the physician billing record for the visit that was associated with the first domperidone prescription. We were able to match $93 \%$ of prescriptions with physician specialty and $80 \%$ of prescriptions with records of related physician visits with information on diagnosis. Differences in the linkage rates stem from prescriptions received at hospital discharge or in non-fee-for-service medical clinics, for which there are no unique physician encounter data. To estimate use potentially associated with gastrointestinal motility disorders, we also examined the prevalence of prior diagnoses of disorders of the stomach (International Classification of Diseases, 9th Revision, code 536) during 1 year preconception and during pregnancy for all women dispensed domperidone during the postpartum period.

Oxytocin nasal spray and metoclopramide can also be used as galactagogues, but the former is not sold in Canada, and there were few postpartum metoclopramide prescriptions in our data set $(<100 / y r)$. Therefore, we did not include any analyses on alternate galactogogues.

\section{Statistical analyses}

We present descriptive statistics for the metrics defined above. We used logistic regression to generate crude and adjusted odds ratios (ORs) and 95\% confidence intervals (CIs) for health, demographic and socioeconomic maternal characteristics associated with postpartum domperidone use. We adjusted for clustering at the level of the mother because some 
women had given birth more than once during our study period. All analyses were performed using Stata version 13.1 and SAS version 9.3.

\section{Ethics approval}

This study was approved by the University of British Columbia's Behavioural Research Ethics Board (H10-01002; Apr. 19, 2010).

\section{Results}

We identified 225532 women who had 320351 live births between Jan. 1, 2002, and Dec. 31, 2011. In 45518 instances, women filled at least 1 domperidone prescription during the first 6 months of the postpartum period. The prevalence of postpartum domperidone use between 2002 and 2011 more than doubled, increasing gradually from $8 \%$ to $19 \%$ for term births and from $17 \%$ to $32 \%$ for preterm births (Figure 1). The mean (SD) and median (interquartile range [IQR]) time to first domperidone prescription postpartum increased, respectively, from 30 (SD 34) and 16 (IQR 9-37) days in 2002 to 35 (SD 40) and 18 (IQR 8-45) days in 2011 from the delivery date.

Prescribed doses rose over time in a similar fashion for both initial and subsequent prescriptions. Figure 2 shows the distribution of daily doses for all domperidone prescriptions in 2002 and 2011. For the initial prescriptions, the median daily dose increased from 60 (IQR 40-80) $\mathrm{mg}$ in 2002 to 80 (IQR 40-80) $\mathrm{mg}$ in 2011; for all prescriptions, it rose from 67 (IQR 40-80) $\mathrm{mg}$ to 80 (IQR 60-80) $\mathrm{mg}$. In 2011, doses in the range of $61-80 \mathrm{mg} / \mathrm{d}$ made up half of all domperidone dispensations in that year, and dispensation for doses of greater than $80 \mathrm{mg} / \mathrm{d}$ almost doubled from $11 \%$ in 2002 to $19 \%$ in 2011. Of all subsequent prescriptions written for the study population in $2002,32 \%$ of them were at a higher dose than initial prescriptions; for 2011, this figure was $26 \%$, reflecting the higher starting dose of initial prescriptions in 2011.

Individual prescription duration was longer in 2011 than in 2002: median duration was 21 (IQR 14-30) days in 2002 and 30 (IQR 15-30) days in 2011. The total number of days of domperidone therapy during the 6-month postpartum period also increased, from a mean of 47 to 59 days. In 2002, $8.8 \%$ of women with live births had prescriptions covering at least 120 of the first 180 days of the postpartum period, increasing to $14 \%$ in 2011. Conversely, the proportion with 15 or fewer days of use decreased from $27 \%$ in 2002 to $14 \%$ in 2011 . Figure 3 illustrates the shift at the population level in both the number of women who took domperidone during the first 6 months postpartum and the duration of domperidone therapy per woman.

Women who were older, had a higher body mass index, had a chronic disease, were first-time mothers, delivered more than 1 baby (multiple pregnancy), had a preterm birth or had a cesarian delivery were more likely to fill a domperidone prescription during the postpartum period (Table 1). There were no large differences by smoking status or by income quintile.

Prepregnancy prescriptions would be expected if women with gastrointestinal problems discontinued use in pregnancy and reinitiated postpartum. However, only $1.5 \%$ of women who used domperidone postpartum had a physician visit for disorders of the stomach during 1 year preconception or during pregnancy. Among first-time mothers who used domperidone postpartum, only $0.4 \%$ had at least 1 domperidone dispensation during 1 year preconception or during pregnancy.

The vast majority (92\%) of both initial and subsequent domperidone prescriptions during the postpartum period were written by general practitioners, with almost all of the remaining $8 \%$ accounted for equally by pediatricians and obstetrician-gynecologists. The most frequent diagnoses recorded as the reason for physician visit associated with initial domperidone prescriptions are listed in Table 2. The top 2 diagnoses,

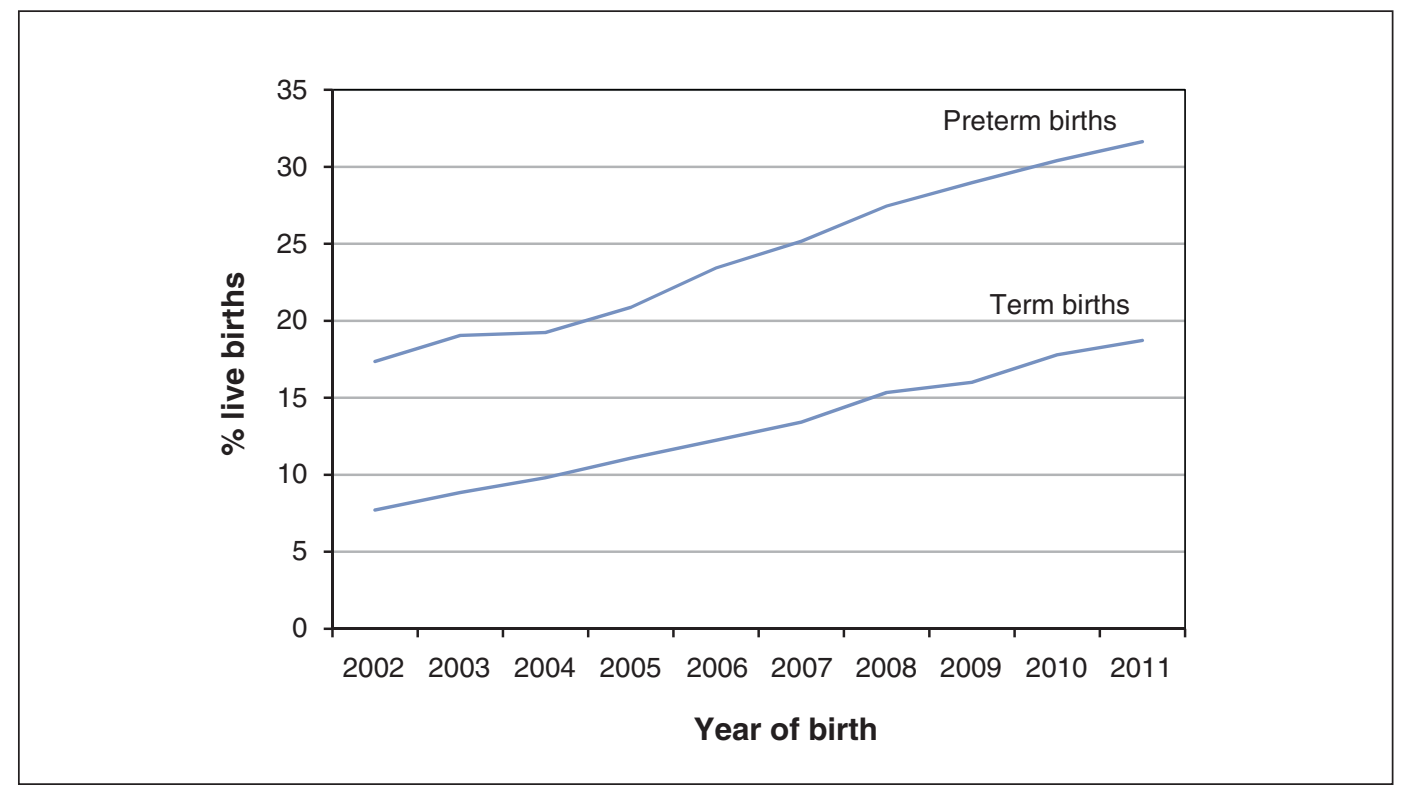

Figure 1: Domperidone use in the first 6 months postpartum among women in British Columbia with live births. 
accounting for $28 \%$ of matched records, were disorders of the breast. Less than $0.1 \%$ of domperidone dispensations were associated with a physician visit for disorders of the stomach.

\section{Interpretation}

Our study identifies an increase in the use of domperidone during the postpartum period among women in BC. Most initial domperidone prescriptions were written by general practitioners, and the most frequent indication for these prescriptions appears to be disorders of the breast.
There is very limited published information on prevalence and trends in postpartum domperidone use. Our findings are consistent with the results of a 2009 study involving a convenience sample of 76 postpartum women attending drop-in clinics in Calgary, Alberta, which found a $28 \%$ rate of domperidone use. ${ }^{26}$ Internationally, 1 report from an Australian hospital with outpatient postpartum services describes increased use over the same period, but at a much lower level: from less than $0.5 \%$ of women in 2000 to $5 \%$ in $2010 .{ }^{27}$ An analysis of prescribing patterns at this hospital indicates broadly similar patterns to those we observed in

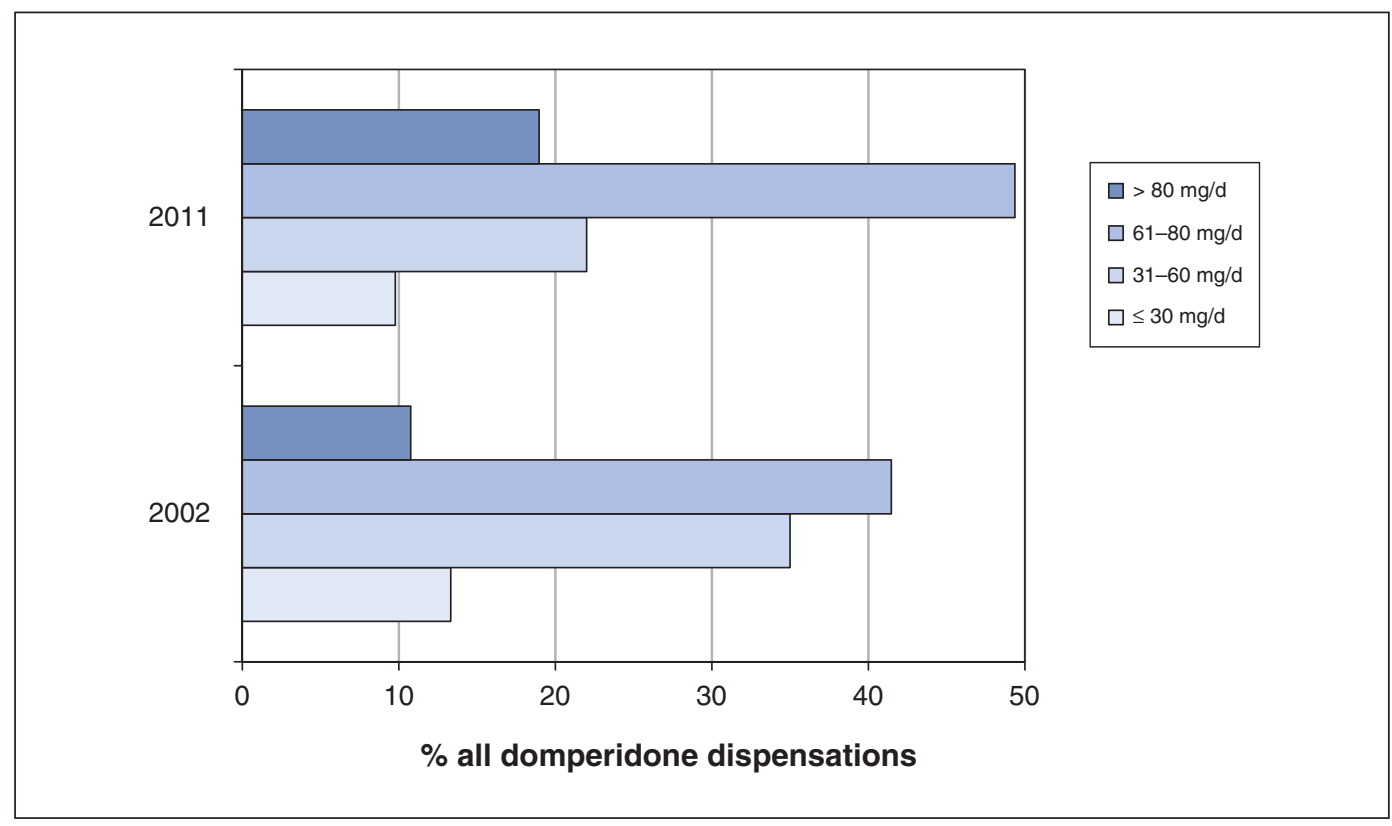

Figure 2: Distribution of daily doses per dispensed domperidone prescription in 2002 and 2011.

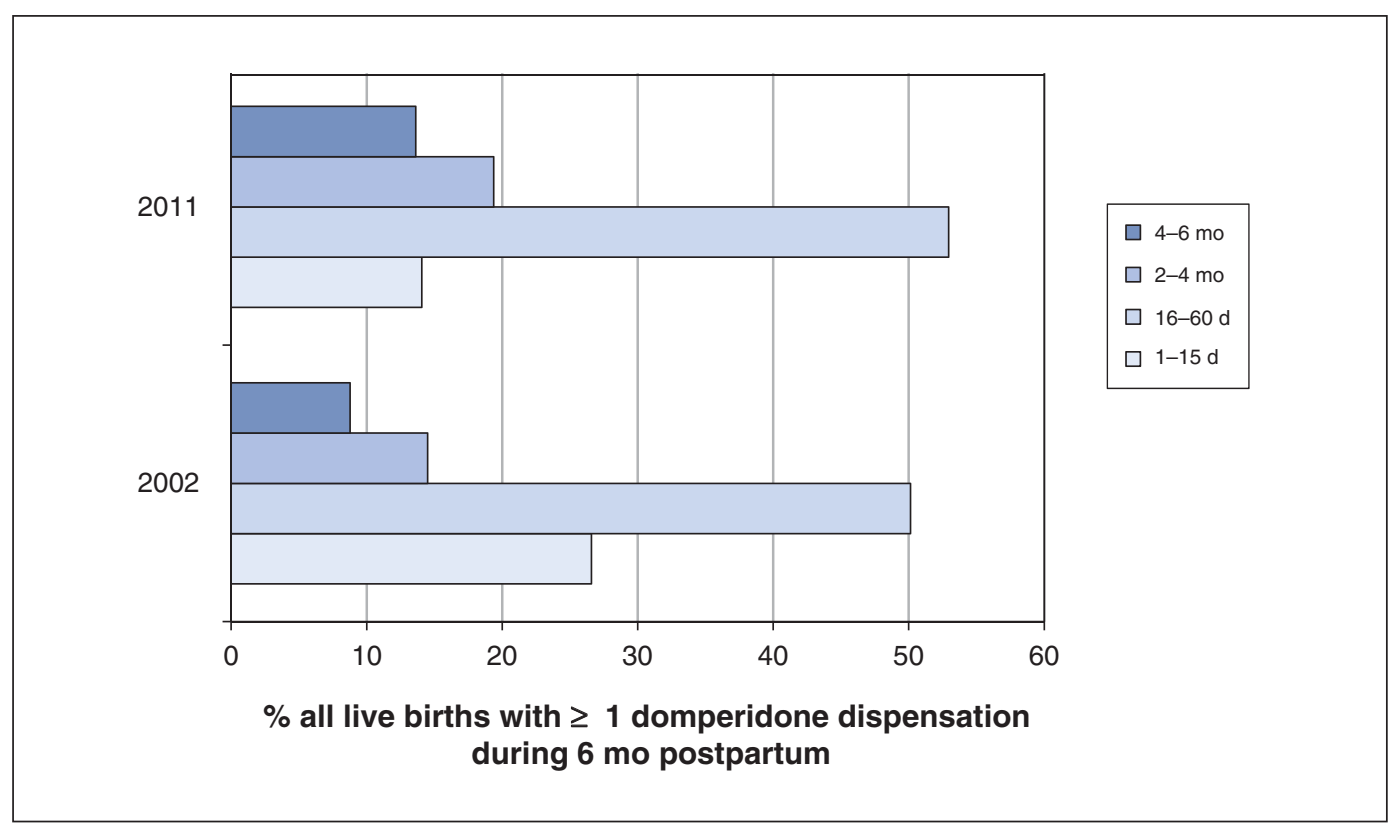

Figure 3: Duration of domperidone therapy during the first 6 months postpartum in 2002 and 2011. 
Table 1: Characteristics of women with a live birth in British Columbia between 2002 and 2011, by postpartum domperidone use Group, no. (\%)*

\begin{tabular}{|c|c|c|c|c|}
\hline \multirow[b]{2}{*}{ Characteristic } & \multicolumn{2}{|c|}{ Group, no. $(\%)^{*}$} & \multirow[b]{2}{*}{$\begin{array}{l}\text { Unadjusted OR } \\
(95 \% \mathrm{Cl})\end{array}$} & \multirow[b]{2}{*}{$\begin{array}{l}\text { Adjusted OR† } \\
\qquad(95 \% \mathrm{Cl})\end{array}$} \\
\hline & $\begin{array}{l}\text { Did not fill a domperidone } \\
\text { prescription, } n=274833\end{array}$ & $\begin{array}{l}\text { Filled } \geq 1 \text { domperidone } \\
\text { prescription, } n=45518\end{array}$ & & \\
\hline \multicolumn{5}{|l|}{ Age, yr } \\
\hline$<25$ & $36196(13.2)$ & $4707(10.3)$ & Ref & Ref \\
\hline $25-29$ & $72928(26.5)$ & $10552(23.2)$ & $1.11(1.07-1.16)$ & $1.22(1.16-1.27)$ \\
\hline $30-34$ & $94811(34.5)$ & $15990(35.1)$ & $1.30(1.25-1.34)$ & $1.51(1.44-1.58)$ \\
\hline $35-39$ & $57116(20.8)$ & $11000(24.2)$ & $1.48(1.42-1.54)$ & $1.79(1.70-1.87)$ \\
\hline$\geq 40$ & $13782(5.0)$ & $3269(7.2)$ & $1.82(1.73-1.92)$ & $2.22(2.08-2.36)$ \\
\hline \multicolumn{5}{|l|}{ Body mass index } \\
\hline < 18.5 (underweight) & $10869(4.0)$ & $1492(3.3)$ & $0.91(0.86-0.97)$ & $0.95(0.89-1.01)$ \\
\hline 18.5-24.9 (normal) & $126799(46.1)$ & $19032(41.8)$ & Ref & Ref \\
\hline 25.0-29.9 (overweight) & $42309(15.4)$ & 7810 (17.2) & $1.23(1.19-1.27)$ & $1.25(1.21-1.29)$ \\
\hline$\geq 30$ (obese) & 22724 (8.3) & 5739 (12.6) & $1.68(1.62-1.74)$ & $1.72(1.66-1.78)$ \\
\hline Unknown & $72132(26.2)$ & $11445(25.1)$ & & \\
\hline \multicolumn{5}{|l|}{ Smoker } \\
\hline No & $250149(91.0)$ & $41513(91.2)$ & Ref & Ref \\
\hline Yes & $24684(9.0)$ & $4005(8.8)$ & $0.98(0.94-1.01)$ & $1.06(1.01-1.11)$ \\
\hline \multicolumn{5}{|l|}{ Income quintile } \\
\hline Lowest & $56255(20.5)$ & $8225(18.1)$ & $0.82(0.79-0.84)$ & $0.90(0.87-0.94)$ \\
\hline 2nd & $54813(19.9)$ & $9119(20.0)$ & $0.93(0.90-0.96)$ & $1.01(0.97-1.05)$ \\
\hline 3rd & $54909(20.0)$ & $8942(19.6)$ & $0.91(0.88-0$ 94) & $0.97(0.93-1.01)$ \\
\hline 4th & $54543(19.8)$ & $9488(20.8)$ & $0.97(0.94-1.00)$ & $1.02(0.99-1.06)$ \\
\hline Highest & 54107 (19.7) & 9706 (21.3) & Ref & Ref \\
\hline \multicolumn{5}{|l|}{ Chronic disease } \\
\hline No & $167129(60.8)$ & 24555 (53.9) & Ref & Ref \\
\hline Yes & 107704 (39.2) & $20963(46.1)$ & $1.32(1.30-1.35)$ & $1.26(1.23-1.29)$ \\
\hline \multicolumn{5}{|l|}{ Parity } \\
\hline 0 & 116294 (42.3) & $26328(57.8)$ & Ref & Ref \\
\hline$\geq 1$ & 158539 (57.7) & $19190(42.2)$ & $0.53(0.52-0.55)$ & $0.48(0.47-0.49)$ \\
\hline \multicolumn{5}{|l|}{ Pregnancy type } \\
\hline Singleton & 271298 (98.7) & $43863(96.4)$ & Ref & Ref \\
\hline Mutiples & 3535 (1.3) & $1655(3.6)$ & $2.90(2.73-3.07)$ & $1.72(1.59-1.86)$ \\
\hline \multicolumn{5}{|l|}{ Gestation, wk } \\
\hline$<36$ (preterm) & $19887(7.2)$ & $6502(14.3)$ & $2.14(2.08-2.21)$ & $1.83(1.76-1.90)$ \\
\hline$\geq 37$ (term) & 254616 (92.6) & 38963 (85.6) & Ref & Ref \\
\hline Mean \pm SD & $38.8 \pm 1.9$ & $38.3 \pm 2.5$ & & \\
\hline \multicolumn{5}{|l|}{ Delivery mode } \\
\hline Vaginal & $194204(70.7)$ & $28231(62.0)$ & Ref & Ref \\
\hline Cesarian & 80629 (29.3) & $17287(38.0)$ & $1.48(1.44-1.50)$ & $1.20(1.17-1.24)$ \\
\hline
\end{tabular}




\begin{tabular}{|llc|}
\hline $\begin{array}{l}\text { Table 2: Top } 4 \text { diagnostic codes recorded on the physician } \\
\text { billing record that occurred closest to the initial postpartum } \\
\text { domperidone dispensation }\end{array}$ \\
\hline ICD-9 code & Associated condition & $\begin{array}{c}\text { \% matched initial } \\
\text { postpartum domperidone } \\
\text { prescriptions }\end{array}$ \\
\hline 611 & $\begin{array}{l}\text { Disorders of the breast } \\
\text { Disorders of the breast } \\
\text { associated with } \\
\text { childbirth, and } \\
\text { disorders of lactation }\end{array}$ \\
\hline 780 & \begin{tabular}{l} 
General symptoms \\
\hline $30 B$
\end{tabular} & 15.9 \\
\hline Pote: ICD-9 $=$ International Classification of Diseases, 9th Revision.
\end{tabular}

$\mathrm{BC}$, including higher rates of domperidone use associated with preterm birth, cesarian delivery, primiparity, older maternal age and obesity.

The reasons for the increase in domperidone use postpartum in BC are likely multifactorial. The rate of exclusive breastfeeding for at least 6 months after birth in BC is the highest in Canada, and it has risen from $28 \%$ to $41 \%$ between 2003 and 2011/12. ${ }^{28}$ Campaigns directed at new mothers and clinicians during the 2000s about the health benefits of breastfeeding may have resulted in domperidone being seen as a solution in the face of potential lactation difficulties. There may have been an increase in demand for domperidone from patients. It is also possible that there has been a snowball effect in prescribing among physicians, with more relaxed prescribing practices becoming widespread in the absence of advisories against domperidone's use as a galactogogue. In Canada, domperidone is available only as a generic drug and is produced by 11 manufacturers. This makes manufacturer-driven promotion an unlikely contributor to off-label postpartum use.

In January 2015, Health Canada recommended domperidone use at no more than $30 \mathrm{mg} / \mathrm{d}$, regardless of indication. ${ }^{13}$ The European Medicines Agency recommends a daily dose of $30 \mathrm{mg}$ or less for no more than 1 week..$^{29}$ This advice differs considerably from the doses and durations we observed in $\mathrm{BC}$ throughout the 2000s. It is possible that the observed dose escalation over the study period reflects inadequate efficacy (perceived or real) at lower doses. A patient information booklet accessed in April 2015 from the BC Women's Hospital lactation clinic, given to all mothers who have trouble breastfeeding, includes an extensive section on domperidone and recommends a daily dose of $30-80 \mathrm{mg}$ for 3-8 weeks. ${ }^{30}$ Similarly, a recent patient information sheet from an Ontario breastfeeding clinic recommends an initial dose of $90 \mathrm{mg} / \mathrm{d}$ and duration of therapy for a minimum of 4-6 weeks. ${ }^{31}$

\section{Limitations}

Given our study design, we could not confirm whether participants were breastfeeding at the time of domperidone dispensation. Secondly, our study measured prescriptions filled and we have no way of tracking drug use. However, it should be noted that dispensation information is a more accurate measure of drug exposure than data on prescriptions written because, for a variety of reasons, many prescriptions written by doctors are not filled by patients. ${ }^{32}$ Further, there is no reason to believe that the proportion of filled prescriptions that are not taken would systematically differ over time.

\section{Conclusion}

We observed an increase in postpartum domperidone prescriptions from 2002 to 2011 as well as increased doses and duration of use. In 2011, 1 in 5 women was prescribed domperidone in the first 6 months after giving birth, with the majority of prescriptions above levels currently considered safe by regulators. Our results suggest routine - and increasing postpartum use of domperidone in the face of uncertain safety to mothers and infants. More research is needed on maternal and infant health outcomes related to domperidone.

\section{References}

1. Slusser $W$. Breastfeeding and maternal and infant health outcomes in developed countries. AAP Grand Rounds 2007;18:15-6.

2. Petraglia F, De Leo V, Sardelli S, et al. Domperidone in defective and insufficient lactation. Eur 7 Obstet Gynecol Reprod Biol 1985;19:281-7.

3. Smolina K, Mintzes B, Oberlander TF, et al. Trends and determinants of prescription drug use during pregnancy and postpartum in British Columbia, 2002-2011: a population-based cohort study. PLoS ONE 2015;10:e0128312.

4. Campbell-Yeo ML, Allen AC, Joseph K, et al. Effect of domperidone on the composition of preterm human breast milk. Pediatrics 2010;125:e107-14.

5. da Silva OP, Knoppert DC, Angelini MM, et al. Effect of domperidone on milk production in mothers of premature newborns: a randomized, double-blind, placebo-controlled trial. CMA7 2001;164:17-21.

6. Inam I, Hashmi A, Shahid A. A comparison of efficacy of domperidone and placebo among postnatal women with inadequate breast milk production. Pakf Med Health Sci 2013;7:314-7.

7. Jantarasaengaram S, Sreewapa P. Effects of domperidone on augmentation of lactation following cesarean delivery at full term. Int 7 Gynaecol Obstet 2012; 116:240-3.

8. Knoppert DC, Page A, Warren J, et al. The effect of two different domperidone doses on maternal milk production. 7 Hum Lact 2013;29:38-44.

9. Wan EWX, Davey K, Page-Sharp M, et al. Dose-effect study of domperidone as a galactagogue in preterm mothers with insufficient milk supply, and its transfer into milk. Br 7 Clin Pharmacol 2008;66:283-9.

10. Asztalos EV, Campbell-Yeo M, Kiss A, et al. Enhancing breast milk production with domperidone in mothers of preterm neonates (EMPOWER trial). BMC Pregnancy Childbirth 2012;12:87-93.

11. Product monograph for ratio-DOMPERIDONE. Toronto: Teva Canada Ltd.; 2012. Available: www.tevacanada.com/ImageAndPdf.ashx? ObjectId $=\mathrm{a} 7 \mathrm{eb} 7 \mathrm{c} 45-1 \mathrm{~d} 5 \mathrm{e}-43 \mathrm{dd}-8300-\mathrm{d} 6158 \mathrm{bd} 94174 \&$ DataType=ProductMonograph PDF\&ObjectMethod=Value\&Language=english (accessed 2015 June 3).

12. Health Canada. Domperidone maleate - association with serious abnormal heart rhythms and sudden death (cardiac arrest) — for health professionals. 2012. Available: www.healthycanadians.gc.ca/recall-alert-rappel-avis/hc-sc/2012/ 15857a-eng.php (accessed 2015 June 3).

13. Health Canada. Domperidone maleate - association with serious abnormal heart rhythms and sudden death (cardiac arrest) — for health professionals. 2015. Available: www.healthycanadians.gc.ca/recall-alert-rappel-avis/hc-sc/2015/ 43423a-eng.php (accessed 2015 June 3).

14. van Noord C, Dieleman JP, van Herpen G, et al. Domperidone and ventricular arrhythmia or sudden cardiac death. Drug Saf 2010;33:1003-14.

15. Johannes CB, Varas-Lorenzo C, McQuay LJ, et al. Risk of serious ventricular arrhythmia and sudden cardiac death in a cohort of users of domperidone: a nested case-control study. Pharmacoepidemiol Drug Saf 2010;19:881-8.

16. Flanders D, Lowe A, Kramer $M$, et al. A consensus statement on the use of domperidone to support lactation. 2012. Available: www.ilca.org/files/CLCA/ PDF/Listserv\% 20pdfs/Domperidone\%20Consensus\%20Statement\%20Final \%20May\%2011\%202012.pdf (accessed 2015 June 3).

17. Bozzo P, Koren G, Ito S. Health Canada advisory on domperidone. Should I avoid prescribing domperidone to women to increase milk production? Can Fam Physician 2012;58:952-3.

18. Djeddi D, Kongolo G, Lefaix C, et al. Effect of domperidone on QT interval in neonates. 7 Pediatr 2008;153:663-6.

19. BC Ministry of Health (MOH). Consolidation file (MSP Registration \& Premium Billing); Discharge Abstracts Database (Hospital Separations); Medical Services Plan 
(MSP) Payment Information File. Vancouver: Population Data BC; 2012-2014.

20. BC Ministry of Health. PharmaNet. Vancouver: Data Stewards Committee; 2014

21. Vital statistics deaths. Vancouver: Population Data BC, BC Vital Statistics Agency; 2012.

22. British Columbia Perinatal Data Registry. Vancouver: Perinatal Services BC; 2014.

23. Frosst G, Hutcheon J, Joseph K, et al. Validating the British Columbia Perinatal Data Registry: a chart re-abstraction study. BMC Pregnancy Childbirth 2015; 15:123-34.

24. Hanley GE, Morgan S. On the validity of area-based income measures to proxy household income. BMC Health Serv Res 2008;8:79-86.

25. Hanley GE, Morgan S, Reid RJ. Explaining prescription drug use and expenditures using the adjusted clinical groups case-mix system in the population of British Columbia, Canada. Med Care 2010;48:402-8.

26. Mannion C, Mansell D. Breastfeeding self-efficacy and the use of prescription medication: a pilot study. Obstet Gynecol Int 2012;2012:562704.

27. Grzeskowiak LE, Lim SW, Thomas AE, et al. Audit of domperidone use as a galactogogue at an Australian tertiary teaching hospital. 7 Hum Lact 2013;29:32-7.

28. Statistics Canada. Chart 3: Rates of exclusive breastfeeding for six months or more by Canada and region, 2003 and 2011-12. In: Canadian Community Health Survey, 2013. Available: www.statcan.gc.ca/pub/82-624-x/2013001/ article/11879/c-g/c-g-03-eng.htm (accessed 2015 June 3).

29. European Medicines Agency Pharmacovigilance Risk Assessment Committee. PRAC recommends restricting use of domperidone. 2014. Available: www.ema .europa.eu/docs/en_GB/document_library/Referrals_document/Domperidone _31/Recommendation_provided_by_Pharmacovigilance_Risk_Assessment _Committee/WC500162559.pdf (accessed 2015 June 3).

30. Increasing your milk supply [patient handout]. Vancouver: Children's \& Women's Health Centre of BC; 2012.

31. International Breastfeeding Centre Toronto. Domperidone, getting started. 2015. Available: www.nbci.ca/index.php?option $=$ com_content $\&$ view $=$ article \&id=
14:domperidone-getting-started-\&catid=5:information\&Itemid=17 (accessed 2015 June 3).

32. Tamblyn R, Eguale T, Huang A, et al. The incidence and determinants of primary nonadherence with prescribed medication in primary care: a cohort study. Ann Intern Med 2014;160:441-50.

Affiliations: School of Population and Public Health (Smolina, Morgan); Department of Obstetrics and Gynaecology (Hanley); Child \& Family Research Institute (Oberlander), University of British Columbia, Vancouver, BC; Faculty of Pharmacy and Charles Perkins Centre (Mintzes), University of Sydney, Australia.

Contributors: All of the authors conceived the study design and approach. Steven Morgan acquired funding and data. Kate Smolina and Barbara Mintzes jointly planned the data analysis on postpartum domperidone use, and Kate Smolina undertook the analysis; Barbara Mintzes and Gillian Hanley carried out the evidence review. Kate Smolina drafted the paper. All of the authors reviewed results, contributed to interpretation and revised the manuscript. All of the authors gave final approval of the version to be published and agreed to act as guarantor of the work.

Funding: This study was supported by a grant from the Canadian Institutes of Health Research (CIHR DC0190GP). Kate Smolina is funded by a CIHR Banting Postdoctoral Fellowship.

Supplemental information: For reviewer comments and the original submission of this manuscript, please see www.cmajopen.ca/content/4/1/ E13/suppl/DC1. 